\title{
Posterior Reversible Encephalopathy Syndrome
}

\author{
Alexandra N. Gewirtz ${ }^{1}$ (D) Virginia Gao ${ }^{1} \cdot$ Sarah C. Parauda ${ }^{1} \cdot$ Matthew S. Robbins $^{1}$ \\ Accepted: 29 December 2020 / Published online: 25 February 2021 \\ (C) The Author(s), under exclusive licence to Springer Science+Business Media, LLC part of Springer Nature 2021
}

\begin{abstract}
Purpose of Review This review provides an updated discussion on the clinical presentation, diagnosis and radiographic features, mechanisms, associations and epidemiology, treatment, and prognosis of posterior reversible encephalopathy syndrome (PRES). Headache is common in PRES, though headache associated with PRES was not identified as a separate entity in the 2018 International Classification of Headache Disorders. Here, we review the relevant literature and suggest criteria for consideration of its inclusion.

Recent Findings COVID-19 has been identified as a potential risk factor for PRES, with a prevalence of $1-4 \%$ in patients with SARS-CoV-2 infection undergoing neuroimaging, thus making a discussion of its identification and treatment particularly timely given the ongoing global pandemic at the time of this writing.

Summary PRES is a neuro-clinical syndrome with specific imaging findings. The clinical manifestations of PRES include headache, seizures, encephalopathy, visual disturbances, and focal neurologic deficits. Associations with PRES include renal failure, preeclampsia and eclampsia, autoimmune conditions, and immunosuppression. PRES is theorized to be a syndrome of disordered autoregulation and endothelial dysfunction resulting in preferential hyperperfusion of the posterior circulation. Treatment typically focuses on treating the underlying cause and removal of the offending agents.
\end{abstract}

Keywords Reversible posterior encephalopathy syndrome $\cdot$ Immunosuppressive drugs $\cdot$ Vasogenic edema $\cdot$ Hypertensive encephalopathy $\cdot$ Headache

\section{Introduction}

Posterior reversible encephalopathy syndrome (PRES) is a clinico-radiological entity that was first described in 1996 in a series of fifteen patients with acute neurological symptoms including headache, seizures, visual disturbances, and other focal neurological deficits [1]. Though it was initially described as a reversible posterior leukoencephalopathy syndrome, PRES has since been the name most commonly applied to this entity. Here, we discuss the clinical presentation, diagnosis and radiographic features, mechanisms, associations and epidemiology, treatments, and prognosis of PRES. In addition, we propose criteria for a PRES-associated

This article is part of the Topical Collection on Secondary Headache

Alexandra N. Gewirtz

ang9221@nyp.org

1 Department of Neurology, New York-Presbyterian Hospital, Weill Cornell Medicine, 525 East 68th Street, New York, NY 10065, USA headache syndrome for consideration by the International Classification of Headache Disorders [2].

\section{Clinical Presentation}

PRES is associated with a wide array of clinical presentations including headaches, focal neurological deficits, seizures, visual disturbances, and encephalopathy. The severity and acuity of clinical symptoms vary, although typically occur with rapid onset.

\section{Headache}

PRES-associated headache was first characterized by Hinchey et al. as sudden in onset, with or without associated neurologic deficits or seizures. It is typically described as constant and dull, at times intractable, and has been reported in $50 \%$ of patients [3,4]. A subset of patients, however, describe a "thunderclap headache" as a harbinger of associated reversible cerebral vasoconstriction syndrome (RCVS) [5]. Headache in conjunction with PRES-associated disease states has been 
reported. Postpartum headache has been described as a recurrent syndrome associated with PRES. [6] In one prospective study of eclampsia patients, the presence of headache predicted abnormal imaging, with $95.6 \%$ of those with headache having abnormal imaging as compared to $12.5 \%$ of those without headache [7]. The most common characterizations of these eclampsia-associated headaches were throbbing or pounding pain (53\%) and pressure like (40\%). Of note, abnormal imaging findings in this study were not limited to PRES, but 16 of the 40 patients in the study had FLAIR abnormalities, a hallmark feature of the syndrome. One study demonstrated $58 \%$ prevalence of headache in preeclampsia/ eclampsia patients with PRES. [8] Headache attributed to arterial hypertension is yet another syndrome associated with PRES and presents as severe in onset in conjunction with notably high blood pressures [9]. Prior reports have described headache in patients with PRES receiving associated medications; however, these patients are usually hypertensive at time of diagnosis $[10,11]$.

\section{Seizures}

Seizures are common in PRES, seen in up to $81 \%$ of patients [4] and most often manifesting as generalized tonic-clonic episodes [12] with a propensity for recurrence. In a retrospective review of 49 patients with PRES, (17.6\%) had recurrent generalized tonic-clonic seizures [13]. The semiology of PRES-associated seizures varies, however, and also includes convulsive status epilepticus (SE), complex partial seizures, and nonconvulsive SE. SE has been observed in up to $17 \%$ of patients with PRES in a larger case series [5]. It occasionally represents symptomatic onset of PRES, as seen in a series of 10 patients with the majority exhibiting focal-onset complex partial SE as the initial presenting complaint [14]. In another study of 11 pediatric patients with PRES undergoing stem cell transplantation, there was a high rate of SE with 12 episodes of SE in 10 patients, 8 cases of convulsive SE and 4 cases of nonconvulsive SE [15]. Seizures, when present, tend to occur early after disease onset in PRES. In a study of 38 patients with PRES and seizures, $100 \%$ had clinical seizures the first day after diagnosis, with no subsequent seizures [13]. Occipital lobe involvement has been identified as a significant predictor of the occurrence of seizures. On multivariate analysis in one study, occipital lobe involvement alone was significantly associated with the occurrence of PRES-related seizure development (OR: 9.63, $p=0.02$ ) [16]. In one prospective study of 40 women with eclampsia, which is defined by the presence of seizures, of the 22 women with MR imaging of the brain, all had T2 abnormalities including 11 with high parietal and 8 with occipital pole abnormalities [7].

\section{Encephalopathy}

PRES can present with encephalopathy and, in one study, was the presenting complaint in $28 \%$ of patients [17]. Encephalopathy is present in most cases with a variable severity and can range from mild confusion to disordered consciousness $[18 \bullet \cdot$. Practically, since seizures are so common in PRES, encephalopathy may also be associated with an ictal or postictal state.

\section{Visual Disturbances}

Visual disturbances are common in PRES and were seen in $39 \%$ of patients in one study [19]. The symptoms can present as cortical blindness, various types of visual field deficits, visual neglect, hallucinations, and blurred vision. Ocular examination in patients with PRES is often unrevealing, although may reveal papilledema on fundoscopic examination along with nonspecific hemorrhages and exudates [20]. In one study of patients with PRES, visual complaints included bilateral vision loss in the majority of patients (64\%), diplopia in $27 \%$, and unilateral vision loss, color desaturation, and pain with extraocular movements each individually found in $9 \%$ of patients. Of note, of those patients with ocular complaints, $100 \%$ had a history of hypertension [21]. Visual symptoms have been theorized to occur with higher frequency with certain associations of PRES. A retrospective review observed that visual disturbances such as cortical blindness, blurred vision, and hemianopia are more common in eclampsiarelated PRES. [8]

Visual recovery appears to be favorable in PRES. In a review of PRES in systemic lupus erythematosus (SLE), visual impairment was found in 15 of 26 episodes, with $87 \%$ of patients completely recovering their vision [22]. In two case reports of PRES and associated visual loss, follow-up results of visual field examination and peripapillary retinal nerve fiber lining were normal [23].

\section{Focal Neurologic Deficits}

Focal neurologic deficits are varied and correlate with location of edema. In the literature, focal neurological symptoms have been reported in $10-15 \%$ of patients with PRES. [17] In one review of 71 patients with PRES, focal deficits were characterized as hemiparesis in $8.5 \%$, followed by hemiplegia and speaking difficulty each in $4.2 \%$ of patients [18••].

\section{Diagnosis and Radiographic Features}

The diagnosis of PRES is typically made with magnetic resonance imaging (MRI) of the brain. Imaging characteristically shows focal regions of symmetric hyperintensities on T2weighted studies most commonly in the parietal and occipital 
lobes, followed by the frontal lobes and the cerebellum. In a large cohort study by Bartynski et al., some degree of involvement of the parieto-occipital regions was seen in $98 \%$ of cases. In their review, imaging findings also included a holohemispheric watershed pattern with involvement of the frontal lobes in $22.8 \%$ of patients as well as a superior frontal sulcus watershed pattern in $27.2 \%$ of patients [24]. Apart from the aforementioned patterns, the less common but welldescribed additional regions of involvement may include the midbrain, pons, medulla, and basal ganglia. PRES has rarely been associated with spinal cord involvement [25]. PRES is also associated with hemorrhage, including small volume hemorrhage, subarachnoid hemorrhage, and hematomas, seen in $15.1 \%$ of cases in one study. Not surprisingly, there was a higher frequency of hemorrhage in those patients on therapeutic anticoagulation or undergoing bone marrow transplant [26]. Susceptibility weighted images (SWI) have also been utilized to assess for the presence of hemorrhage, seen in $64.5 \%$ of patients in another review [27]. Abnormal apparent diffusion coefficient is seen in approximately $20 \%$ of cases $[28 \cdot \bullet]$ and has been associated with poor outcomes.

Vasculopathy is a common finding in patients with PRES. Angiography, if performed, can show evidence of constriction of the blood vessels, which suggests a possible overlap with reversible cerebral vasoconstriction syndrome (RCVS). Conversely, typical PRES imaging findings have been reported in 17-38\% patients with RCVS [29].

In a series of 99 cases with PRES, $38 \%$ of patients had extensive vasogenic edema, $21 \%$ had brainstem edema, and $37 \%$ had evidence of intracranial hemorrhage - all classified as advanced radiologic PRES. Of the 94 cases with available MRIs, $16 \%$ had restricted diffusion on T2, also considered an advanced radiologic sign of PRES. Extensive vasogenic edema and the presence of hemorrhage were both associated with a low modified Rankin Scale (mRS) score at discharge ( $p=$ 0.047 and 0.021 , respectively). The presence of diffusion restriction also showed a trend towards association with poor $\mathrm{mRS}$ at discharge $(p=0.074)$. Overall, the presence of advanced radiologic PRES was associated with both poor discharge disposition $(p=0.021)$ and poor $\mathrm{mRS}$ at discharge $(p=0.008)[30]$.

\section{Mechanisms}

PRES is a disorder of dysregulated perfusion, leading to usually reversible vasogenic edema. There are several theories as to why the cerebrovasculature becomes dysregulated in PRES. There is no single mechanism that explains the development of PRES in all cases, and multiple nonexclusive mechanisms likely contribute.

In cases where hypertension is a key feature, hyperperfusion is thought to play a critical role. In response to fluctuations in systemic blood pressure, cerebrovascular autoregulation preserves cerebral blood flow, leading to vasodilation during systemic hypotension and vasoconstriction during systemic hypertension. Rapid development of hypertension can exceed the capacity of cerebral blood flow autoregulation leading to hyperperfusion. Consistent with the clinical and radiographic features of the disease, posterior brain regions are thought to be more vulnerable to hyperperfusion because there is less sympathetic innervation to the posterior circulation, potentially through reduced opposition to parasympathetic reflex vasodilation. Whether the systemic blood pressures seen in patients with PRES can truly overwhelm autoregulatory mechanisms has been questioned $[18 \cdot \bullet$. Among patients who have PRES and hypertension, less than $50 \%$ have a mean arterial pressure (MAP) above the upper limit of cerebral blood flow autoregulation derived from physiological studies, MAP $>140-150$ [31]. However, there may be individual and circumstantial variability. For example, arterial hypertension, acute fluctuations in blood pressure, and autonomic activity can all shift autoregulatory thresholds. Autoregulatory curves may also be shifted in pregnancy, making it a particularly vulnerable time for PRES despite only modest elevations in blood pressure.

On a mechanistic level, blood-brain barrier breakdown can result from hyperperfusion and increased cerebral perfusion pressure leading to extravasation of plasma and macromolecules into the interstitial space through tight junction proteins [32]. Other mechanisms also contribute to the loss of the integrity of the vascular endothelium, which can lead to vasoconstriction in and of itself. The release of vasoactive substances including nitric oxide, thromboxane A2, or endothelin-1 from the vascular endothelium contributes to cerebral autoregulation [33]. Thromboxane A2 and endothelin-1 can mediate cerebral vasospasm and lead to blood pressure elevations. It has further been proposed that hypertension may also result from hyperperfusion caused by endothelial dysfunction or another systemic process. However, as development of hypertension usually precedes development of symptoms, this does not provide a unifying explanation. Indeed, hyperperfusion due to hypertension cannot explain the development of PRES in the $15-20 \%$ of patients who have normotension or hypotension [32].

Endothelial damage is also implicated in PRES. Vascular integrity is normally preserved by inter-endothelial adhesion molecules, and circulating toxins can trigger vascular leakage and edema. In immune disorders and other systemic disorders, release of cytokines including tumor necrosis factor alpha (TNF $\alpha$ ), interleukin-1 (IL1), and interferon gamma (IFN $\gamma$ ) activates the secretion of vasoactive factors from endothelial cells that increase vascular permeability leading to interstitial edema. The release of these cytokines can also influence downstream gene expression cascades. TNF $\alpha$ and IL1 induce the expression of adhesion molecules, including intracellular adhesion molecule 1 (ICAM-1), vascular cell adhesion protein 
1 (VCAM-1), and E-selectin, that interact with circulating leukocytes and lead to endothelial activation [34]. Similarly, in infection, polymorphonuclear leukocytes are activated, marginate to the vessel wall, adhere to the vascular endothelium, and increase vascular permeability. TNF $\alpha$ also induces the expression of vascular endothelial growth factor (VEGF), which is thought to independently increase vascular permeability [33]. Elevated levels of VEGF have been implicated in a number of disease states associated with PRES, most notably SLE. Kuryliszyn-Moskal et al. showed that patients with SLE have significantly higher levels of VEGF than healthy controls $(p<0.05)$ [35]. In addition, in patients with SLE and PRES, brain biopsies were performed that showed evidence of endothelial activation and subsequent VEGF expression, suggesting a possible relationship between PRES and VEGF levels [36]. Hypoxia has also been associated with the development of PRES. Release of endothelial factors in response to hypoxia promotes angiogenesis (including VEGF) and this breakdown of the blood-brain barrier has been postulated to contribute to vasogenic edema.

Taken together, and depending on the clinical situation, all these mechanisms may contribute to the development of PRES pathophysiology (Fig. 1).

\section{Epidemiology and Associations}

PRES is seen in all age groups with a range from 4 to 90 years [37] and a mean age of 45 [4]. In adults, there is a female predominance of cases even after exclusion of patients with eclampsia [17]. The prevalence in the pediatric population has not been well established, although a prior study of 2588 admissions to a pediatric critical care unit reported a rate of $0.4 \%$ [38]. Another study of 825 pediatric hospitalizations for PRES-associated conditions such as bone marrow transplant, hypertension, and connective tissue disorders found the rate of PRES to be $0.04 \%$ [39].

\section{Renal Injury/Failure}

Many studies suggest renal injury is the strongest predictor of the development of PRES - up to 55\% of cases are associated with renal failure $[17,18 \bullet \bullet, 40]$. In a retrospective study of 63 SLE patients, renal failure was the only independent predictor of the development of PRES. [40] Similarly, a case series involving thrombotic thrombocytopenic purpura (TTP) and PRES revealed glomerular filtration rate to be the only laboratory value with a significant association with the presence of PRES on brain MRI [41]. The mechanisms tying kidney injury to PRES have yet to be fully elucidated but may involve disruption in the renin-angiotensin-aldosterone system (RAAS). Another theory suggests that upregulation and accumulation of vasopressin in kidney failure may play a role in arteriole vasoconstriction and failure of autoregulation in PRES. [42]

\section{COVID-19}

The combination of disordered cerebrovascular autoregulation, acute renal failure, acute hypertension, hypoxia, inflammation, and endothelial injury can characterize SARS-CoV-2 infection and its sequelae. Coincidence of PRES and COVID19 disease has been reported, making recognition and diagnosis of PRES particularly timely. Along with the common use of immunomodulatory medications, these associated characteristics make this pandemic disease a perfect storm for the development of PRES. [43, 44] A larger study of 278 patients with confirmed COVID-19 undergoing imaging demonstrated a $1.1 \%$ prevalence of PRES. MRI as an imaging modality had a higher yield in detecting cases, demonstrating a 3.9\% prevalence of PRES. [45]

\section{Preeclampsia/Eclampsia}

The obstetric complications of preeclampsia and eclampsia are closely linked with PRES. In one study, 97.9\% of patients with eclampsia had confirmed PRES on imaging [46], suggesting that the disease entities are essentially one and the same, with the eclampsia diagnosis existing long before imaging modalities were available. Widespread endothelial dysfunction in combination with abrupt elevations in blood pressure is thought to be the key features that drive PRES in preeclampsia and eclampsia [47]. In women with preeclampsia or eclampsia, those with PRES also have a higher prevalence of thrombocytopenia and proteinuria as compared to those without PRES. [48] However, PRES associated with these etiologies appears to have some key differences compared to PRES attributed to other etiologies. One study showed that patients with PRES associated with these conditions have a significantly higher prevalence of headaches (58\% vs. 18\%) and lower incidence of altered mental status (12.5\% vs. $45 \%)$ as compared to patients with PRES associated with non-obstetric conditions [8]. Additionally, this study found that in this population, imaging showed less involvement of T2 hyperintensities in the thalamus, midbrain, and pons; lower incidence of hemorrhage and diffusion restriction; as well as less severe edema when compared to those patients with PRES associated with other etiologies. However, other studies have not found such differences in imaging findings $[49,50]$.

\section{Autoimmune Conditions and Hemoglobinopathies}

Almost half of PRES patients have an associated autoimmune condition, including SLE, TTP, Crohn's disease, and scleroderma, among others $[18 \bullet \cdot$. However, it is difficult to 


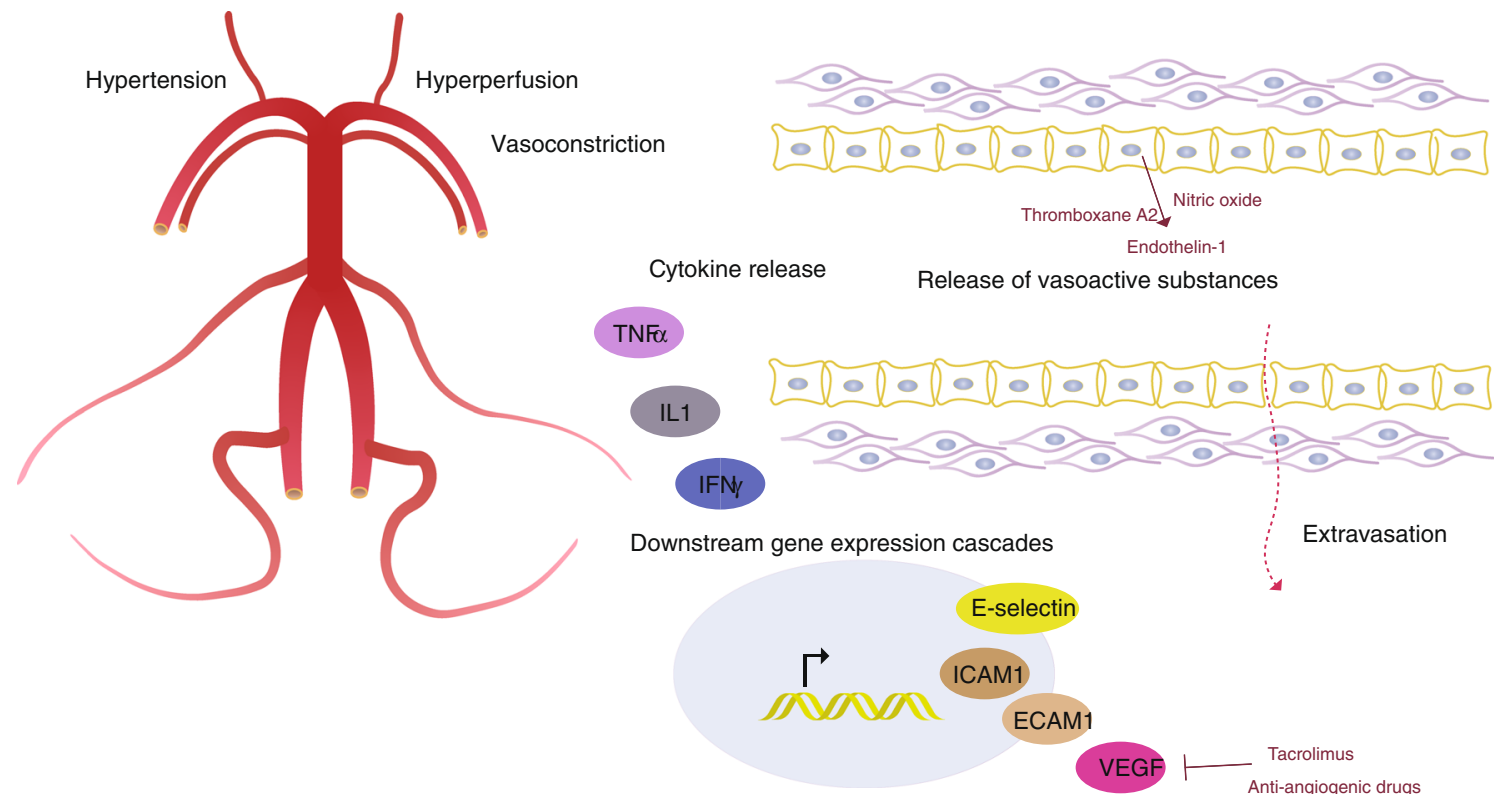

Fig. 1 Mechanisms contributing to the development of PRES. Disordered cerebrovascular autoregulation in hypertension can lead to hyperperfusion. Blood-brain barrier breakdown results from increased cerebral perfusion pressure leading to extravasation of plasma and macromolecules into the interstitial space through tight junction proteins.

determine if the root of the association is the autoimmune disease itself or rather the high incidence of renal injury as well as the immunosuppressive medications frequently used in these conditions. PRES has also been reported in a series of patients with neuromyelitis optica, and it has been postulated that disordered fluid shifts play a role in pathogenesis in these patients with abnormal function of aquaporin 4 [51]. Both solid organ and stem cell transplant patients have high incidence of PRES, with incidence in solid organ transplantation varying from 0.4 and $6 \%$ [52] and in hematopoietic stem cell transplantation between 1.1 and 22\% [53-55]. Graft-versus-host disease associated with transplant also appears to increase risk for PRES. [55] PRES has been reported in individuals with sickle cell disease (SCD), typically in those with acute chest syndrome as well as post stem cell transplant patients on calcineurin inhibitors. In the pediatric population, PRES has been seen in children independently of acute chest syndrome. In a retrospective review of MRI findings in 80 children with SCD, 8 patients had radiologic and clinical characteristics consistent with PRES. [39] It is not clear whether PRES is independently associated with SCD or whether the underlying vasculopathy, hypertension, and endothelial damage contribute [56].

\section{Immunosuppression and Other Associated Medications}

Classically, the immunosuppressive medications highly associated with PRES are the calcineurin inhibitors tacrolimus and
Release of cytokines activates the secretion of vasoactive factors from endothelial cells that increase vascular permeability leading to interstitial edema. Release of these cytokines can also influence downstream gene expression cascades

cyclosporine, though this may be via induction of hypertension and/or impaired autoregulation as blood levels do not seem to correlate with incidence $[18 \bullet \bullet, 42]$. Steroids have both been implicated in the improvement of PRES-associated vasogenic edema and in the development of PRES itself [57]. Tocilizumab has also been reported in association with PRES. [57, 58] Hydroxychloroquine has also been implicated in PRES, though it is unclear if this is an independent risk factor or simply associated via its common use as a treatment for SLE $[17,59,60]$. Finally, several VEGF antagonists have been associated with PRES - bevacizumab, sunitinib, and sorafenib [18••, 61].

\section{Treatment and Prognosis}

There are no clinical trials to date regarding the treatment of PRES. Withdrawal or management of the offending trigger such as hypertension, impaired renal function, or immunosuppressive therapies appears to improve outcomes. Systemic blood pressure abnormalities, if untreated, can lead to development or exacerbation of cerebral edema. Correspondingly, aggressive blood pressure management in cases of hypertension-induced PRES has been shown to reduce associated morbidity [62]. In cases of pregnancy-associated PRES, management includes expeditious delivery of the infant. In pregnant women with PRES and preeclampsia, magnesium sulfate is indicated to prevent seizures [5]. 
In cases of calcineurin inhibitor-associated PRES, a common strategy is the replacement of the offending calcineurin inhibitor with other immunosuppressive agents (43.7\% in one study). Other strategies include replacement with another calcineurin inhibitor $(26.8 \%)$; replacement with sirolimus, everolimus, mycophenolate mofetil, or hydrocortisone (16.9\%); or lowering the dose of the offending agent $(22.5 \%)$. In only $9.9 \%$ of cases, discontinuation of the agent with no replacement was pursued [63]. Other studies suggest that continuation of the same calcineurin inhibitor or changing to alternative calcineurin inhibitors is well tolerated. In one study of patients with hematologic disorders, the majority of patients (77\%) tolerated continuation or alternative calcineurin inhibitor therapy. An additional $11 \%$ tolerated conversion from a calcineurin inhibitor to sirolimus, with only $8 \%$ of patients experiencing recurrent PRES with continuation of calcineurin or sirolimus therapy [64].

Steroid therapy has not been shown to play a role in the routine treatment of PRES-associated vasogenic edema. In a study of 99 cases of PRES, corticosteroid therapy frequently preceded the onset of PRES and was not significantly associated with the extent of vasogenic edema, suggesting that it does not lessen edema and may in fact contribute to the development of PRES. [56]

Treatment of malignant complications of PRES is also paramount, such as IV anticonvulsants in status epilepticus and aggressive management of hemorrhagic PRES and increased intracranial pressure. Management of PRES often requires an ICU setting; in one study, $70 \%$ of patients with PRES required ICU care for PRES-associated complications including status epilepticus [65]. The optimal agent and length of treatment in PRES-associated seizures, however, remains controversial [66].

Prognosis is generally favorable and the majority of patients make a full recovery, though some diagnostic criteria require clinical and radiographic resolution [18••] which does not include the entire spectrum of the disease. When reversibility is not mandated, complete recovery is reported in 75$90 \%$ of cases, and most patients will recover within a week, though in some patients, recovery occurs over a longer interval and neurological sequelae have been reported in 10-20\% of patients [9]. PRES can also be quite severe, and mortality has been reported in 3-6\% of cases [67]. Etiology of severe neurologic injury and death include intracranial hemorrhage, edema in the posterior fossa leading to hydrocephalus or brainstem compression, or increased intracranial pressure. The underlying cause of PRES, time to treatment, and underlying imaging characteristics have all been shown to contribute to prognosis $[4,68]$. As previously mentioned, a retrospective review of 99 cases with PRES showed that the presence of advanced radiologic PRES was associated with both an unfavorable discharge disposition and poor $\mathrm{mRS}$ at discharge [30].
Table 1 Proposed diagnostic criteria: headache attributed to posterior reversible encephalopathy syndrome (PRES)

Any new headache fulfilling the following criteria and continuous for $>=$ $72 \mathrm{~h}$ without treatment or continuous for $<72 \mathrm{~h}$ with treatment

1. Posterior reversible encephalopathy syndrome has been diagnosed

2. Evidence of causation demonstrated by either or both of the following:

a. Headache has developed in close temporal relation to other symptoms and/or clinical signs of PRES, or has led to the diagnosis of PRES

b. Headache has significantly improved in parallel with stabilization or improvement of other symptoms or clinical or radiological signs of PRES

3. Not better accounted for by another ICHD-3 diagnosis

Headache attributed to reversible cerebral vasoconstriction syndrome (ICHD-3 code 6.7.3) and headache attributed to arterial hypertension (ICHD-3 code 10.3) can also be diagnosed

\section{Proposed New Criteria for PRES-Associated Headache}

While some cases of PRES are likely captured under ICHD-3 "10.3.3. Headache attributed to hypertensive encephalopathy," hypertensive encephalopathy and PRES are not equivalent diagnoses. About $30 \%$ of PRES cases are associated with normal or only mildly elevated blood pressure values [69, 70]. Many of these PRES cases end up being attributed to other known associations including immunosuppressive and cytotoxic medications, sepsis, autoimmune disorders, and renal failure [70]. Also, while the majority of patients with hypertensive encephalopathy will have altered mental status, this is not so with a significant portion of PRES cases [71]. In particular, PRES cases associated with preeclampsia and eclampsia have lower incidence of altered mental status and higher incidence of headache compared to PRES cases associated with other causes [8]. While some cases of PRES-associated headache may be captured under ICHD-3 10.3.4-Headache attributed to preeclampsia or eclampsia, these are again overwhelmingly entwined with hypertension [8]. As the ICHD-3 currently stands, there is still a significant diagnostic gap for headache that is associated with PRES but not associated with either hypertensive encephalopathy or preeclampsia/ eclampsia.

\section{Conclusions}

Posterior reversible encephalopathy syndrome (PRES) is a clinico-radiological syndrome with a complex clinical presentation. Early recognition of classic radiographic features is vital to prompt recognition and treatment, as the symptoms are relatively nonspecific and the differential diagnosis is broad.

Fifty percent of patients will present with nonspecific headache as previously discussed. To date, headache secondary to 
PRES is not listed as a distinct entity in the ICHD-3, though related conditions are including headache attributed to arterial hypertension and headache attributed to preeclampsia or eclampsia. We propose that PRES-associated headache should be its own unique diagnosis in the ICHD-3 under "6.7: Headache attributed to other acute intracranial arterial disorder" as seen in Table 1.

\section{Compliance with Ethical Standards}

Conflict of Interest The authors declare that they have no conflict of interest.

Human and Animal Rights and Informed Consent This article does not contain any studies with human or animal subjects performed by any of the authors.

\section{References}

Papers of particular interest, published recently, have been highlighted as:

•- Of major importance

1. Hinchey J, Chaves C, Appignani B, Breen J, Pao L, Wang A, et al. A reversible posterior leukoencephalopathy syndrome. N Engl J Med. 1996;334(8):494-500.

2. Arnold M. Headache classification committee of the international headache society (ihs) the international classification of headache disorders. Cephalalgia. 2018;38(1):1-211.

3. Granata G, Greco A, Iannella G, Granata M, Manno A, Savastano E, et al. Posterior reversible encephalopathy syndrome - insight into pathogenesis, clinical variants and treatment approaches. Autoimmun Rev. 2015;14(9):830-6.

4. Legriel S, Schraub O, Azoulay E, Hantson P, Magalhaes E, Coquet I, et al. Determinants of recovery from severe posterior reversible encephalopathy syndrome. PLoS One. 2012;7(9):e44534.

5. Hinduja A. Posterior reversible encephalopathy syndrome: clinical features and outcome. Front Neurol. 2020;11:71.

6. Effendi M, Rashidi A, Ahmad MZ, Yusoff HM, bin Amir Hamzah, A. Postpartum headache: an unexpected manifestation of posterior reversible encephalopathy syndrome. Eurasian Journal of Emergency Medicine. 2016;15(2):108-10.

7. Shah AK, Rajamani K, Whitty JE. Eclampsia: a neurological perspective. J Neurol Sci. 2008;271(1-2):158-67.

8. Liman TG, Bohner G, Heuschmann PU, Scheel M, Endres M, Siebert E. Clinical and radiological differences in posterior reversible encephalopathy syndrome between patients with preeclampsiaeclampsia and other predisposing diseases. Eur J Neurol. 2012;19(7):935-43.

9. Frick D, Huecker M, Shoff H. Posterior reversible encephalopathy syndrome presenting as stroke mimic. Clinical practice and cases in emergency medicine. 2017;1(3):171-4.

10. Hamid M, Ghani A, Micaily I, Sarwar U, Lashari B, Malik F. Posterior reversible encephalopathy syndrome (PRES) after bevacizumab therapy for metastatic colorectal cancer. Journal of community hospital internal medicine perspectives. 2018;8(3): $130-3$.

11. Macdonald DR. Posterior reversible encephalopathy syndrome: case report. Reactions. 2014;1528:162-22.
12. Spencer D. PRES-ing for answers about long-term seizure risk in patients with posterior reversible encephalopathy syndrome: PRESing for answers about long-term seizure risk. Epilepsy currents. 2015;15(6):317-8.

13. Kastrup O, Gerwig M, Frings M, Diener HC. Posterior reversible encephalopathy syndrome (PRES): electroencephalographic findings and seizure patterns. J Neurol. 2012;259(7):1383-9.

14. Kozak OS, Wijdicks EFM, Manno EM, Miley JT, Rabinstein AA. Status epilepticus as initial manifestation of posterior reversible encephalopathy syndrome. Neurology. 2007;69(9):894-7.

15. Cordelli DM, Masetti R, Bernardi B, Barcia G, Gentile V, Biagi C, et al. Status epilepticus as a main manifestation of posterior reversible encephalopathy syndrome after pediatric hematopoietic stem cell transplantation. Pediatr Blood Cancer. 2012;58(5):785-90.

16. Hinduja A, Habetz K, Raina SK, Fitzgerald RT, Sahaya K. Predictors of seizures in patients with posterior reversible encephalopathy syndrome. Epilepsy Behav. 2016;61:97-101.

17. Fugate, J. E., Claassen, D. O., Cloft, H. J., Kallmes, D. F., Kozak, O. S., \& Rabinstein, A. A. (2010, May). Posterior reversible encephalopathy syndrome: associated clinical and radiologic findings. In Mayo Clinic Proceedings (Vol. 85, no. 5, pp. 427-432). Elsevier.

18.• Fugate JE, Rabinstein AA. Posterior reversible encephalopathy syndrome: clinical and radiological manifestations, pathophysiology, and outstanding questions. The Lancet Neurology. 2015;14(9): 914-25 This study provides a thorough analysis of PRES and discusses the main radiologic patterns, current theories of pathophysiology, and clinical outcomes.

19. Lee VH, Wijdicks EF, Manno EM, Rabinstein AA. Clinical spectrum of reversible posterior leukoencephalopathy syndrome. Arch Neurol. 2008;65(2):205-10.

20. Chou MCY, Lee CY, Chao SC. Temporary visual loss due to posterior reversible encephalopathy syndrome in the case of an endstage renal disease patient. Neuro-ophthalmology. 2018;42(1):359.

21. Lifson N, Pasquale A, Salloum G, Alpert S. Ophthalmic manifestations of posterior reversible encephalopathy syndrome. NeuroOphthalmology. 2019;43(3):180-4.

22. Lai CC, Chen WS, Chang YS, Wang SH, Huang CJ, Guo WY, et al. Clinical features and outcomes of posterior reversible encephalopathy syndrome in patients with systemic lupus erythematosus. Arthritis care \& research. 2013;65(11):1766-74.

23. Baranowski D, Rejdak K, Kiszka A, Nowomiejska K, Rejdak R. Vision deterioration in posterior reversible encephalopathy syndrome (PRES). Ophthalmology Journal. 2017;2(2):61-7.

24. Bartynski WS, Boardman JF. Distinct imaging patterns and lesion distribution in posterior reversible encephalopathy syndrome. Am J Neuroradiol. 2007;28(7):1320-7.

25. Saad AF, Chaudhari R, Wintermark M. Imaging of atypical and complicated posterior reversible encephalopathy syndrome. Front Neurol. 2019;10:964.

26. Hefzy HM, Bartynski WS, Boardman JF, Lacomis D. Hemorrhage in posterior reversible encephalopathy syndrome: imaging and clinical features. Am J Neuroradiol. 2009;30(7):1371-9.

27. McKinney AM, Sarikaya B, Gustafson C, Truwit CL. Detection of microhemorrhage in posterior reversible encephalopathy syndrome using susceptibility-weighted imaging. Am J Neuroradiol. 2012;33(5):896-903.

28.• Tetsuka S, Ogawa T. Posterior reversible encephalopathy syndrome: a review with emphasis on neuroimaging characteristics. Journal of the neurological sciences. 2019;404:72-9 This reference focuses on the imaging characteristics of PRES and discusses the various MRI patterns found in the disease.

29. Pilato F, Distefano M, Calandrelli R. Posterior reversible encephalopathy syndrome and reversible cerebral vasoconstriction syndrome: clinical and radiological considerations. Front Neurol. 2020;11:34. 
30. Schweitzer AD, Parikh NS, Askin G, Nemade A, Lyo J, Karimi S, et al. Imaging characteristics associated with clinical outcomes in posterior reversible encephalopathy syndrome. Neuroradiology. 2017;59(4):379-86.

31. Li Y, Gor D, Walicki D, Jenny D, Jones D, Barbour P, et al. Spectrum and potential pathogenesis of reversible posterior leukoencephalopathy syndrome. J Stroke Cerebrovasc Dis. 2012;21(8):873-82.

32. Rabinstein AA, Mandrekar J, Merrell R, Kozak OS, Durosaro O, Fugate JE. Blood pressure fluctuations in posterior reversible encephalopathy syndrome. J Stroke Cerebrovasc Dis. 2012;21(4): 254-8.

33. Creager, M., Loscalzo, J., \& Beckman, J. A. (2012). Vascular medicine E-book: A companion to Braunwald's heart disease. Elsevier Health Sciences.

34. Pruitt JH, Copeland EM III, Moldawer LL. Interleukin-1 and interleukin-1 antagonism in sepsis, systemic inflammatory response syndrome, and septic shock. Shock. 1995;3(4):235-51.

35. Kuryliszyn-Moskal A, Klimiuk PA, Sierakowski S, Ciołkiewicz M. Vascular endothelial growth factor in systemic lupus erythematosus: relationship to disease activity, systemic organ manifestation, and nailfold capillaroscopic abnormalities. Arch Immunol Ther Exp. 2007;55(3):179-85.

36. Carvalho JF, Blank M, Shoenfeld Y. Vascular endothelial growth factor (VEGF) in autoimmune diseases. J Clin Immunol. 2007;27(3):246-56.

37. Chen TH. Childhood posterior reversible encephalopathy syndrome: Clinicoradiological characteristics, managements, and outcome. Front Pediatr. 2020;8.

38. Raj S, Overby P, Erdfarb A, Ushay HM. Posterior reversible encephalopathy syndrome: incidence and associated factors in a pediatric critical care population. Pediatr Neurol. 2013;49(5):335-9.

39. Khademian Z, Speller-Brown B, Nouraie SM, Minniti CP. Reversible posterior leuko-encephalopathy in children with sickle cell disease. Pediatr Blood Cancer. 2009;52(3):373-5.

40. Jung SM, Moon SJ, Kwok SK, Ju JH, Park KS, Park SH, et al. Posterior reversible encephalopathy syndrome in Korean patients with systemic lupus erythematosus: risk factors and clinical outcome. Lupus. 2013;22(9):885-91.

41. Burrus TM, Mandrekar J, Wijdicks EF, Rabinstein AA. Renal failure and posterior reversible encephalopathy syndrome in patients with thrombotic thrombocytopenic purpura. Arch Neurol. 2010;67(7):831-4.

42. Largeau B, Le Tilly O, Sautenet B, Gandonnière CS, Barin-Le Guellec C, Ehrmann S. Arginine vasopressin and posterior reversible encephalopathy syndrome pathophysiology: the missing link? Mol Neurobiol. 2019;56(10):6792-806.

43. Parauda SC, Gao V, Gewirtz AN, Parikh NS, Merkler AE, Lantos J, et al. Posterior reversible encephalopathy syndrome in patients with COVID-19. J Neurol Sci. 2020;416:117019.

44. Anand P, Lau KV, Chung DY, Virmani D, Cervantes-Arslanian AM, Mian AZ, et al. Posterior reversible encephalopathy syndrome in patients with coronavirus disease 2019: two cases and a review of the literature. J Stroke Cerebrovasc Dis. 2020;29(11):105212.

45. Lin E, Lantos JE, Strauss SB, Phillips CD, Campion TR, Navi BB, et al. Brain imaging of patients with COVID-19: findings at an academic institution during the height of the outbreak in New York City. Am J Neuroradiol. 2020;41:2001-8.

46. Brewer J, Owens MY, Wallace K, Reeves AA, Morris R, Khan M, et al. Posterior reversible encephalopathy syndrome in 46 of 47 patients with eclampsia. Am J Obstet Gynecol. 2013;208(6):468e1.

47. McDermott M, Miller EC, Rundek T, Hurn PD, Bushnell CD. Preeclampsia: association with posterior reversible encephalopathy syndrome and stroke. Stroke. 2018;49(3):524-30.
48. Fisher N, Saraf S, Egbert N, Homel P, Stein EG, Minkoff H. Clinical correlates of posterior reversible encephalopathy syndrome in pregnancy. The Journal of Clinical Hypertension. 2016;18(6): $522-7$.

49. Mueller-Mang C, Mang T, Pirker A, Klein K, Prchla C, Prayer D. Posterior reversible encephalopathy syndrome: do predisposing risk factors make a difference in MRI appearance? Neuroradiology. 2009;51(6):373-83.

50. Roth C, Ferbert A. Posterior reversible encephalopathy syndrome: is there a difference between pregnant and non-pregnant patients? Eur Neurol. 2009;62(3):142-8.

51. Magaña SM, Matiello M, Pittock SJ, McKeon A, Lennon VA, Rabinstein AA, et al. Posterior reversible encephalopathy syndrome in neuromyelitis optica spectrum disorders. Neurology. 2009;72(8): $712-7$.

52. Staykov D, Schwab S. Posterior reversible encephalopathy syndrome. J Intensive Care Med. 2012;27(1):11-24.

53. Gaziev J, Marziali S, Paciaroni K, Isgrò A, Di Giuliano F, Rossi G, et al. Posterior reversible encephalopathy syndrome after hematopoietic cell transplantation in children with hemoglobinopathies. Biology of Blood and Marrow Transplantation. 2017;23(9):153140.

54. Hammerstrom AE, Howell J, Gulbis A, Rondon G, Champlin RE, Popat U. Tacrolimus-associated posterior reversible encephalopathy syndrome in hematopoietic allogeneic stem cell transplantation. Am J Hematol. 2013;88(4):301-5.

55. Chen Q, Zhao X, Fu HX, Chen YH, Zhang YY, Wang JZ, et al. Posterior reversible encephalopathy syndrome (PRES) after haploidentical haematopoietic stem cell transplantation: incidence, risk factors and outcomes. Bone Marrow Transplant. 2020:1-8.

56. Farooq S, Testai FD. Neurologic complications of sickle cell disease. Current Neurology and Neuroscience Reports. 2019;19(4):17.

57. Parikh NS, Schweitzer AD, Young RJ, Giambrone AE, Lyo J, Karimi S, et al. Corticosteroid therapy and severity of vasogenic edema in posterior reversible encephalopathy syndrome. J Neurol Sci. 2017;380:11-5.

58. Rosa Júnior M, Borges ÉI, Fonseca APA, Fiorot JL, Balarini L, Valim V. Posterior reversible encephalopathy syndrome during treatment with tocilizumab in juvenile idiopathic arthritis. Arq Neuropsiquiatr. 2018;76(10):720-1.

59. Leroux G, Sellam J, Costedoat-Chalumeau N, Le Thi Huong D, Combes A, Tieulié N, et al. Posterior reversible encephalopathy syndrome during systemic lupus erythematosus: four new cases and review of the literature. Lupus. 2008;17(2):139-47.

60. Gatla N, Annapureddy N, Sequeira W, Jolly M. Posterior reversible encephalopathy syndrome in systemic lupus erythematosus. Journal of clinical rheumatology : practical reports on rheumatic \& musculoskeletal diseases. 2013;19(6):334 40.

61. Tlemsani C, Mir O, Boudou-Rouquette P, Huillard O, Maley K, Ropert S, et al. Posterior reversible encephalopathy syndrome induced by anti-VEGF agents. Target Oncol. 2011;6(4):253-8.

62. Servillo G, Bifulco F, De Robertis E, Piazza O, Striano P, Tortora F, et al. Posterior reversible encephalopathy syndrome in intensive care medicine. Intensive Care Med. 2007;33(2):230-6.

63. Song T, Rao Z, Tan Q, Qiu Y, Liu J, Huang Z, et al. Calcineurin inhibitors associated posterior reversible encephalopathy syndrome in solid organ transplantation: report of 2 cases and literature review. Medicine. 2016;95(14):e3173.

64. Cerejo, M. C., Barajas, R. F., Cha, S., \& Logan, A. C. (2014). Management strategies for posterior reversible encephalopathy syndrome (PRES) in patients receiving calcineurin-inhibitor or sirolimus therapy for hematologic disorders and allogeneic transplantation.

65. Hinduja A, Habetz K, Raina SK, Fitzgerald RT. Predictors of intensive care unit utilization in patients with posterior reversible encephalopathy syndrome. Acta Neurol Belg. 2017;117(1):201-6. 
66. Skiba V, Etienne M, Miller JA. Development of chronic epilepsy after recurrent episodes of posterior reversible encephalopathy syndrome associated with periodic lateralized epileptiform discharges. Seizure. 2011;20(1):93-5.

67. Liman TG, Bohner G, Endres M, Siebert E. Discharge status and inhospital mortality in posterior reversible encephalopathy syndrome. Acta Neurol Scand. 2014;130(1):34-9.

68. Covarrubias DJ, Luetmer PH, Campeau NG. Posterior reversible encephalopathy syndrome: prognostic utility of quantitative diffusion-weighted MR images. AJNR Am J Neuroradiol. 2002;23:1038-48.
69. Feske SK. Posterior reversible encephalopathy syndrome: a review. Semin Neurol. 2011;31(2):202-15.

70. Fischer M, Schmutzhard E. Posterior reversible encephalopathy syndrome. J Neurol. 2017;264(8):1608-16.

71. Miller JB, Suchdev K, Jayaprakash N, Hrabec D, Sood A, Sharma $\mathrm{S}$, et al. New developments in hypertensive encephalopathy. Curr Hypertens Rep. 2018;20(2):13.

Publisher's Note Springer Nature remains neutral with regard to jurisdictional claims in published maps and institutional affiliations. 